\title{
CUATRO SIGLOS DE CUIDADOS TRANSCULTURALES
}

\section{Rosa María Rodríguez Perales. Profesora de Enfermería Comunitaria* Juan Manuel Arribas Marín. Profesor de Fundamentos de Enfermería e Historia de la Enfermería*} José Carlos Gantes Soto. Profesor de Enfermería Psiquiátrica y de Salud Mental* * Escuela Universitaria de Enfermería y Fisioterapia San Juan de Dios. Integrada en la Universidad Pontificia Comillas de Madrid.

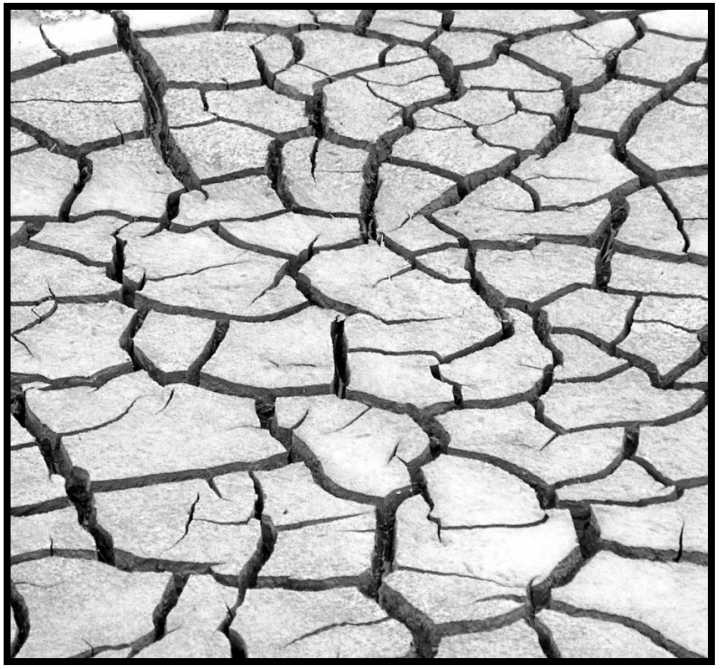

FOUR CENTURIES OF TRANSCULTURAL CARE

\section{ABSTRACT}

Founded in the XVIth century, since 1608 the Hospitalary Order of Saint John of God has spread its work to different countries with the aim of caring for patients without distinguishing race, nation, religion or disease. At the present time, it looks after people from different cultures with a particular style established by the founder of the institution.

In this article we analyze the principles that determine its own institutional culture: humanization, hospitality, solidarity, love, charity, justice, liberty, dignity, communication and listening. All of them are basic for working within cultural diversity and essential for the development of transcultural care and for the practise of modern nursing. Nursing from a Saint John of God perspective implies a humanistic and transcultural care based on the welfare of people providing a great stream of solidarity that will allow a change of attitudes and of the present unfair establishment.

Key words: humanization, hospitality, transcultural care, Saint John of God culture, nursing.

\section{RESUMEN}

Fundada en el siglo XVI, desde 1608 la Orden Hospitalaria San Juan de Dios ha extendido su labor a diferentes países con el objetivo de dispensar asistencia sin distinguir raza, nación, religión ni enfermedad. En la actualidad cuida a personas de diferentes culturas, con una impronta y un estilo propio marcado por su fundador. A lo largo de estos casi cinco siglos ha estado al servicio del necesitado, determinando un modelo asistencial, de gestión y de formación enfermera que toma como base el humanismo y cuyo desarrollo se concreta en compaginar: Ciencia y Técnica con Humanización y Hospitalidad.

En este artículo se analizan los valores y principios que definen su cultura institucional: HUMANIZACIÓN, HOSPITALIDAD, SOLIDARIDAD, AMOR, CARIDAD, JUSTICIA, LIBERTAD, DIGNIDAD, COMUNICACIÓN, ESCUCHA, fundamentales para trabajar en la diversidad cultural e imprescindibles para el desarrollo de cuidados transculturales, para la práctica enfermera que nos exige el presente y el futuro de nuestra 
sociedad multicultural. La atención de enfermería desde una perspectiva juandediana implica ofrecer un cuidado humanístico y transcultural, centrado en el bienestar de las personas que facilite una gran corriente de solidaridad entre los pueblos y permita caminar hacia un cambio de actitudes que transforme las estructuras actuales injustas.

Palabras clave: humanización, hospitalidad, cuidados transculturales, cultura juandediana, enfermería.

En el momento social actual, en un mundo cambiante y multicultural, pleno de transformaciones sociales, en el que cada vez aumenta el número de inmigrantes de diferentes culturas que viven en nuestro país, que precisan cuidados que valoren sus creencias, costumbres y prácticas, que exige convivencia plural y plantea dificultades de comunicación e interacción, y en el que la enfermería debe trabajar diagnosticando e interviniendo en estas múltiples realidades, es fundamental desarrollar líneas de trabajo que abran caminos a las nuevas generaciones, en la búsqueda de la excelencia y la calidad, desde una perspectiva juandediana.

Fundada en el siglo XVI, desde 1608 la Orden Hospitalaria San Juan de Dios ha extendido su labor a diferentes países con el objetivo de dispensar asistencia sin distinguir raza, nación, religión ni enfermedad. A partir del primer centro abierto en Granada en 1538 ha ido ampliándose y creciendo hasta hoy. En la actualidad cuida a personas de diferentes culturas en todo el mundo, está presente en 49 naciones, formando parte de la misma 1.215 hermanos, 40.000 trabajadores y voluntarios, y más de 300.000 colaboradores-bienhechores, en un total de 389 obras dedicadas fundamentalmente a la atención de enfermos, pobres y necesitados (Orden Hospitalaria de San Juan de Dios, 2004), con una impronta y un estilo propio marcado por su fundador.

Juan Ciudad Duarte, (1495-1550), creaba enfermería, hablaba sobre los cuidados que se debían dar a los necesitados, trabajaba en respuesta a las necesidades de los individuos de forma paradigmática, marcaba el futuro de la enfermería profesional y transcultural (Castro, 1585). La Orden Hospitalaria que él fundó, ha aportado a esta disciplina líneas de trabajo y principios éticos que han potenciado los cuidados profesionales enfermeros de calidad, y sigue desarrollando en la actualidad, en diferentes realidades, políticas, civiles y religiosas, un estilo propio de hacer enfermería, que tiene en cuenta la diversidad cultural de cada grupo social, no sólo en relación a los inmigrantes extranjeros sino también a los adolescentes, a los ancianos, y a diferentes grupos sociales, ya que cada uno de ellos tiene una imagen y concepción del mundo distinta, construye su realidad socialmente y de forma diferente al otro, tiene una parcela cultural propia que comparte con la comunidad a la que pertenece.

Desde una perspectiva social y antropológica una cultura se entiende, no como cúmulo de conocimientos sino, como define Rocher, un conjunto trabado de maneras de pensar, sentir y de obrar más o menos formalizadas, que aprendidas y compartidas por una pluralidad de personas sirven de un modo objetivo y simbólico a la vez, para constituir a esas personas en una colectividad particular y distinta (Rocher, 1979). Constituye un conjunto de imágenes o concepciones del mundo elaboradas y transmitidas socialmente que se comparten y utilizan en una sociedad específica en un determinado momento histórico, para hacer frente al ambiente.

La cultura entendida, por tanto, como la realidad vivida por las personas, sus concepciones del entorno, su código de leyes, sus reglas y normas sociales, sus símbolos compartidos, su lenguaje, en definitiva todo aquello que le permite la comunicación y la vida en sociedad y que adquiere mediante el aprendizaje. Ningún elemento cultural se hereda biológicamente, es todo lo que un individuo debe aprender para vivir en una sociedad particular. La cultura desempeña en el hombre la misma función de adaptación a sí mismo y al entorno, que el instinto desempeña en el animal. La supervivencia del individuo depende básicamente no de la vida de la naturaleza, sino de la sociedad (kahn, 1975), de su socialización.

Mediante el proceso de socialización la persona aprende e interioriza en el transcurso de su vida los elementos socioculturales de su medio ambiente, los integra a la estructura de su personalidad bajo la influencia de experiencias y de agentes sociales significativos y se adapta al entorno social 
en cuyo seno debe vivir, este proceso, como señalan Berger y Luckamann, implica la internalización de la sociedad en cuanto tal y de la realidad objetiva en ella establecida, y, al mismo tiempo, el establecimiento subjetivo de una identidad coherente y continua (Berger, 1978), y comprende lógicamente representaciones del cuerpo, de la salud, de la enfermedad y del cuidado.

Existen distintos modelos culturales aprendidos durante este proceso, que circulan por las distintas redes del tejido social, que establecen diferentes maneras de conocer, opinar, creer y comportarse en lo que respecta a la higiene, la alimentación, el sueño, la sexualidad, el trabajo, las drogas, el ejercicio, etc., y que originan reacciones emocionales distintas en relación a patologías específicas, valoración de síntomas, percepción del dolor, etc. que producen en definitiva diferentes riesgos, demandas y cuidados de salud, originando un complejo mosaico cultural.

La enfermedad es función de la cultura, evidentemente sobre una base biológica, pero no basta con que uno esté enfermo, es necesario que la sociedad lo sancione como tal (Ackernecht 1985), si es de otro modo, la enfermedad o el suceso pasaran inadvertidos o se interpretaran en otro contexto de referencia y no se tratara de buscar ni una etiología ni una terapia. La enfermedad, que siempre tiene un contenido biológico, es un modo de expresión cultural, un mensaje a descifrar. La salud y la enfermedad son conceptos socialmente construidos, la cultura los define y tipifica, así como asigna un determinado significado al hecho de estar enfermo o sano y hace que se asocie a ello una determinada consideración social. Cada cultura, a su vez, crea su propio contexto terapéutico, es decir señala las alternativas y circunstancias más adecuadas para recuperar la salud, como también los procedimientos para conseguir esta recuperación (Durán 1983).

Los conceptos de cultura y cuidado están íntimamente relacionados. Cuidar es tan viejo como el mundo y tan cultural como la diversidad que caracteriza la humanidad, como refiere RohrbachViadas (2004). La esencia del trabajo de enfermería es cuidar. Los cuidados relacionados con la salud que universalmente podemos denominar cuidados o atención de enfermería, son un aspecto funcional de la sociedad y han variado con ella desde sus orígenes. La práctica del cuidado es un fenómeno universal, pero las expresiones, procesos y modelos de cuidados varían de una cultura a otra. Han existido como instinto de conservación de los pueblos desde que el ser humano existe y ha necesitado de cuidados para subsistir. Se han llevado a cabo en todas las comunidades y en todas las épocas, pero de forma diversa, ya que el proceso salud-enfermedad es un fenómeno social, y no se considera la misma enfermedad ni se tiene la misma visión de ella en todas las comunidades, ya sea entre sus distintos grupos, o entre dos momentos históricos de un mismo grupo. La teoría de los cuidados transculturales de Leininger trata de la importancia de prestar cuidados de enfermería según sea la cultura del paciente al que se le está brindando el cuidado (Manrique, 2004).

A lo largo de estos casi cinco siglos, la Orden ha ido adaptándose a los diferentes momentos históricos, a las innovaciones y demandas de la sociedad en cada período y lugar en el mundo. "y porq nuestro intéto es desear ampliar mas la dicha Hospitalidad, y cúplir con ella en la mejor forma, acomodandonos con los tiempos, y necesidades prefentes [sic]" (Quintanilla, 1650). Ha prestado cuidados, tanto a las personas enfermas o en situaciones especiales de su ciclo de vida, de diferentes grupos sociales, países y épocas, en función de sus demandas y situaciones de salud, de los criterios de causalidad atribuidos por cada pueblo a sus enfermedades, de los conocimientos científicos del momento, de la profesionalización y formación de los cuidadores y de su cultura.

Desde sus orígenes hasta hoy la organización juandediana ha contribuido al proceso de cambio enfermero de forma innegable, unificando la metodología de los cuidados en todos sus centros, consolidando un estilo propio, sin abandonar el carisma primigenio que infundió su fundador y que fue plasmado en las Constituciones primitivas, basadas en las primeras normas prácticas que éste planteó (Orden Hospitalaria de San Juan de Dios, 1585). Siempre, y en todos los lugares del mundo, la Orden Hospitalaria San Juan de Dios ha estado al servicio del necesitado, determinando un modelo asistencial, de gestión y de formación enfermera que toma como base el humanismo Juandediano y 
cuyo desarrollo se concreta en compaginar: Ciencia y Técnica con Humanización y Hospitalidad, y que a través de diferentes procesos de socialización, del curriculum formal y del curriculum oculto, han adquirido los profesionales de enfermería que se han formado en sus centros.

Estos principios y valores son imprescindibles para el desarrollo de los cuidados, para la práctica enfermera que nos exige el presente y el futuro de nuestra sociedad multicultural. En estos momentos en los que se habla de nuevas formas de entender nuestra disciplina, de la importancia de conocer la diversidad cultural y de incorporar valores humanistas al cuidado de las personas, la cultura institucional de la orden que define la práctica enfermera juandediana es cultura de humanización.

Los problemas de salud de la población de este siglo que acaba de comenzar necesitan cuidados integrales y transculturales, científicos y humanistas, precisan de profesionales que entiendan y respeten los valores culturales, las creencias y prácticas de los individuos, que hayan adquirido contenidos, procedimientos y actitudes para realizar una atención de enfermería de calidad y proporcionar cuidados culturalmente apropiados siguiendo el modelo hospitalario de San Juan de Dios. Los Hermanos han trabajado en todo el mundo en situaciones conflictivas de pobreza y violencia y ahora todas esas situaciones "están en casa".

Los valores y principios que definen su cultura institucional se basan en conceptos como: HUMANIZACIÓN, HOSPITALIDAD, SOLIDARIDAD, AMOR, CARIDAD, JUSTICIA, LIBERTAD, DIGNIDAD, COMUNICACIÓN, ESCUCHA, fundamentales para trabajar en la diversidad cultural (Orden Hospitalaria de San Juan de Dios 2000).

La palabra humanización aplicada a la asistencia sanitaria nació en esta Orden Hospitalaria y considera esencial para su práctica la humanización de los profesionales, que deben tener un proyecto ético de asistencia, y de las instituciones, que deben ser transparentes, abiertas, creer en el trabajo en equipo, atender a la formación e información, y utilizar la comunicación como pilar fundamental en las relaciones laborales. Es humanizarse para humanizar, conseguir que desde el interior de cada uno de nosotros y de las organizaciones emerja hacia el exterior una manera de hacer que sitúe al necesitado en el centro de toda atención.

La acción de humanizar es definida por el Calixto Plúmed Moreno, como la asunción de los constitutivos más débiles del hombre que son los que aproximan a la realidad del mismo, para descubrir de manera intermitente los elementos constitutivos de otros niveles humanos (Plumed 2002). Es lograr responder a las necesidades y expectativas de los otros, a su cultura, a su manera de entender la realidad, a partir del conocimiento de lo más profundo de nuestro ser, de nuestros valores, de nuestro equilibrio personal y de nuestra propia autorrealización.

Es tener conciencia de la complejidad humana, con lo cual no reduciremos a la persona a la mínima parte de sí mismo, ni al peor fragmento de su pasado, sino que descubriremos los múltiples aspectos que cada uno de nosotros trae en su condición de humano. Humanización como acercamiento al individuo. Olvidar el etnocentrismo que todos llevamos dentro (Lévi-Strauss, 1979), no creernos superiores e imponer nuestra cultura a los demás, sino ser sensible y apreciar los valores, creencias, estilos de vida, prácticas y estrategias de resolución de problemas de la cultura de los clientes.

Trabajar observando, dialogando y participando plenamente de la cultura de los otros y con los otros, lo que en antropología se denomina "observación participante" que implica convivencia y una cierta unión con el otro, como señalan García Ferrando y Sanmartín, es "nativizarse" sin perder la propia cultura, ampliando, por tanto, las variables capaces de manejar, los conceptos, categorías y valores desde los que se define y aprecia la experiencia, transformando o reelaborando la complejidad del código desde el que se interpreta el sentido de los hechos (García, 1989). Este proceso debe incluir el conocimiento de los propios valores, prejucios que cada uno tiene hacia las otras culturas y una exploración profunda hacia la propia y es indispensable para la práctica de la enfermería transcultural.

La enfermera/o juandediana, respeta y esta alerta a todas las diferencias culturales, patrones de conducta y estilos de vida, que existen en su comunidad, conoce el ambiente social en dónde viven los individuos, sus costumbres locales, etc., relati- 
viza y esta abierta al otro. Desarrolla esa mirada antropológica, necesaria para comprender en toda su complejidad todo aquello relacionado con la salud y la enfermedad, ya que estos conceptos varían en el espacio y en el tiempo y dependen de factores sociales, políticos, geográficos y económicos que caracterizan a cada grupo humano. La vida en una determinada sociedad nos hace enfermar de diferentes maneras, pero también cada grupo social decide de las cosas que le pasan cuál de ellas es enfermedad, y hay que conocerlas e investigarlas desde un perspectiva etic, estudiando hechos verificables, categorías de análisis cuantitativas válidas para la comparación intercultural, y desde el estudio emic que ayuda no sólo a entender la cultura o el lenguaje, sino a comprender a los actores, sus actitudes, motivaciones, intereses y respuestas ya que analiza el fundamento de la comunicación, sus significaciones y sentidos (Harris, 1981).

La humanización juandediana es un modo de hacer que coloca al necesitado, sea de la cultura que sea, en el primer lugar, en el centro la atención enfermera priorizando sus derechos y deberes, esté donde esté. Es fundamentalmente una actitud empática con el otro, es considerar como señala el Pierluigi Marchesi o.h. que ser con el enfermo es más importante que hacer por el enfermo, no pasar de largo junto al hombre, impedir la inhumana división entre persona y enfermedad (Marchesi, 1981), es identificarse a cualquier ser humano porque es humano, aunque sea de otra cultura, es preocuparse por prestarle cuidados integrales, aceptación y respeto, sensibilidad para entender las diferencias y habilidad para ofrecer estrategias acordes con las necesidades del otro.

Hospitalidad, emblema de la Orden, significa sentido de acogida y acompañamiento a la persona en las diferentes situaciones. Implica apertura y disponibilidad para recibir, compartir los momentos de angustia, la pérdida, el dolor. Se basa en tratar de comprender las tensiones y emociones, de ser sensible al sufrimiento. Implica algo más que dar comida y cama a aquel que lo necesita, incluye recibir con un aliento de afecto y de esperanza, proteger, ayudar, respetar, acompañar, dar nuestra presencia amistosa, dar seguridad y confianza, convertir en definitiva a todas las categorías de necesitados y sufrientes en objeto de cuidados.
Conlleva actuar solidariamente con todo enfermo o acogido. Tratar a toda persona con la misma atención independiente de su condición social, desde la construcción solidaria y espiritual de la sociedad, desde la comunión de bienes y la reconciliación entre diferentes ideologías, culturas y enemigos. Es respetar los principios de la justicia social (Orden Hospitalaria de San Juan de Dios, 2000).

La hospitalidad de San Juan de Dios abrió nuevos caminos a la enfermería y a la sociedad. Creó un modelo alternativo de ser enfermero que en la actualidad sigue vigente y que avanza día a día. Se basa en la creatividad, en responder siempre de forma integral a las necesidades nuevas que no despiertan la sensibilidad de los demás (disminuidos físicos y psíquicos, inmigrantes, "sin techo"...) llevando a cabo acciones preventivas, curativas, de emergencia, rehabilitadoras y educadoras, desarrollando proyectos de atención, formación e inserción social, (huérfanos y prostitutas) adaptándose siempre a las circunstancias de lugar, tiempo y persona, (enfermos de SIDA, tóxicodependientes, terminales...), en definitiva a todo contexto cultural.

La humanización y la hospitalidad como acciones orientadas al bienestar de la persona a su felicidad, desde su libertad y dignidad. Cuidar con sabiduría, fuerza, prudencia, dar esperanza y ayuda material y espiritual. Tener humildad, paciencia, compresión, respeto, responsabilidad y benevolencia. Establecer procesos de comunicación adecuados y esencialmente escuchar y comprender, mas que evaluar, establecer un proceso de reconocimiento de competencias y capacidades mutuas, un modelo abierto a la participación entendida como implicación en la adquisición de conocimientos y mutua confianza en la capacidad de resolver los problemas.

El profesional de enfermería juandediano desde sus orígenes, valora los diversos aspectos de la comunicación, y sabe que sus realidades no son las únicas existentes. Cuida la empatía, se esfuerza por especificar y clarificar los significados, manteniendo un escucha activa y participativa, una relación positiva con la comunidad que posibilite a ésta conocer sus problemas y necesidades de salud y decidir sobre ellas. Establece un modelo de reciprocidad en la relación, basado en la colaboración activa, y no en la autoridad y/o diferencia, en la 
que no existan juicios prematuros, proyección de características propias, prejuicios y falta de atención. Intenta no oír lo que espera oír, ni ver lo que espera ver.

Una mirada desde esta perspectiva ofrece al profesional de enfermería, numerosas claves para entender mejor su labor y la forma en que ésta puede ser más eficaz. Le ayuda a conocer a la gente, a saber qué siente, cómo se relaciona, cómo define lo que le pasa, cómo aprende... y a valorar los factores culturales que influyen en los procesos de cuidado con el individuo. Para esto es imprescindible no creer que se sabe todo sobre lo que esta comunidad ignora, sino reconocer, como hace el antropólogo, que ignora todo sobre lo que la comunidad sabe.

El trabajo enfermero seguido por la Orden desarrolla tareas para, en y con la comunidad, con la participación de las personas interesadas. Se basa en el conocimiento y comprensión del otro, en la construcción en común de la intervención. La práctica enfermera juandediana, la que se centra en el hombre, comparte valores humanos con los no creyentes y credo con los creyentes, conforma un servicio integral de salud dirigido al hombre, familia o grupo centrado en el restablecimiento del equilibrio armónico que posibilita el adecuado crecimiento y desarrollo de la persona en su totalidad. Tiene predilección por los más necesitados, por los que viven en sí mismos la experiencia dolorosa de la enfermedad, la soledad, la pobreza, el desamor, situaciones todas que suelen darse en la población emigrante. Integra en el quehacer cotidiano enfermero valores que ayudan a favorecer las relaciones interpersonales y la amistad. Una cultura de humanización se mueve en la civilización del amor, afirma el hermano Calixto Plúmed (2002), y cuidar implica comprender y ello, necesariamente, incluye un proceso de empatía, identificación y proyección e intersubjetividad, precisa de apertura, simpatía, generosidad y amor.

Si la antropología nos ayuda a conocer a los distintos pueblos, estudia la forma en que los individuos de las diferentes culturas y grupos sociales se explican a sí mismos las causas de la enfermedad, los tipos de tratamientos en los que creen y los medios y cuidados a los que recurren cuando se siente enfermos, si se considera labor fundamental del antropólogo el trabajo de campo, es decir, la observación de grupos humanos desde la convivencia con ellos durante largo tiempo para intentar comprender a fondo los problemas que se propone estudiar, el profesional de enfermería juandediano incorpora a su trabajo estrategias de diálogo permanente con la población, que le ayudan a desarrollar su actividad educativa y asistencial. Valora la cultura y los procesos de comunicación que se dan en la comunidad, para poder realizar procesos de promoción de la salud y prevención de la enfermedad eficaces.

Los cuidados enfermeros del siglo XXI deben integrar los avances científicos y tecnológicos con la ética profesional. Los valores y principios que definen la cultura institucional de esta Orden Hospitalaria, reflejada en su Carta de Identidad, basados en la búsqueda constante de asistencia integral científica, humanizada y bien realizada, se asientan en conceptos que deben ser referentes para el desarrollo de la enfermería del futuro. El carácter cambiante, pluralista y diverso de nuestra sociedad, hace necesario considerar en la dimensión transcultural de la atención de enfermería, la perspectiva juandediana, para ofrecer un cuidado humanístico, centrado en el bienestar de las personas que facilite una gran corriente de solidaridad entre los pueblos y permita caminar hacia un cambio de actitudes que transforme las estructuras actuales injustas.

Los problemas de salud de la población de este siglo que acaba de comenzar, necesitan cuidados integrales y transculturales, científicos y humanistas, precisan de profesionales que hayan adquirido conocimientos, habilidades y actitudes siguiendo el modelo que desde el siglo XVI hasta hoy ha desarrollado la Orden Hospitalaria de San Juan de Dios, respetando siempre las formas de cada cultura que tienen expresiones distintas de la misma realidad.

\section{BIBLIOGRAFÍA}

ACKERNECHT, E. H., (1985) Medicina y antropología social. Akal/Universitaria. Madrid, p.17.

BERGER, P. Y LUCKMANN, T., (1978) La construcción social de la realidad. Amorrortu. Buenos Aires, p.169.

CASTRO, F. DE, (1585) Historia de la vida y sanctas obras de Juan de Dios. Ed. En casa de Antonio de Librixa. Granada. 
DURÁN, M. A., (1983) Desigualdad social y enfermedad. Tecnos. Madrid, p.18-19.

GARCÍA FERRANDO M., IBAÑEZ J., ALVIRA F. (1989) (compilación). El análisis de la realidad social" Ed. Alianza Universidad. Madrid. p. 134.

HARRIS M. (1981) El desarrollo de la teoría antropológica. Ed. Siglo XXI. P. 491-504

KAHN J.S. (1975). El concepto de cultura. Anagrama. Barcelona. p. 126-127

LÉVI-STRAUSS, C. (1979) Antropología Estructural. Ed. Siglo XXI. México p. 308-312

MARCHESI, P.L., (1981) La Humanización, Secretariado Interprovincial de España, Madrid, p. 25-32.

MANRIQUE, M; REYES, I; DELGADO, H Y JIMÉNEZ, B. MADELEINE LEININGER. Cuidados Culturales: Teoria de la diversidad y Universalidad [http://www.enfermeria21.com/listametas/Leininger_m ono grafia.doc] (página). 18 de marzo de 2004.

Orden Hospitalaria de San Juan de Dios. (1585). Primitivas Constituciones. Reimpresión 1977.

Orden Hospitalaria de San Juan de Dios. Carta de Identidad. La asistencia a los enfermos y necesitados según el estilo de San Juan de Dios. Roma, 8 de Marzo de 2000.

PLUMED, C. (2002) "Principios y valores que sustentan la Calidad", Documentación Social, 128. Julioseptiembre.

PLUMED, C. 2002. "Pier Luigi Marchesi. Profeta Polémico", Hoja Homenaje, Madrid.

QUINTANILLA, M O.H. (1650) Propuesta hecha al Consejo de Castilla para estender la curación del mal venereo estableciendo los sudores [sic]. Archivo Interprovincial de los Pisa de Granada.

ROCHER, G. (1979), Introducción a la sociología general. Herder. Barcelona, p.111-112.

ROHRBACH-VIADAS, C. Cuidar es tan antiguo como el mundo y tan cultural como la diversidad de la humanidad. [http://departamento.enfe.ua.es/internet/cultura/numero2/antropo1.html] (página). 2 de marzo de 2004.

Secretaría General de la Orden Hospitalaria de San Juan de Dios, (2004) Estadística 2003, Familia Hospitalaria, Suplemento de Juan Ciudad 487, p.5.

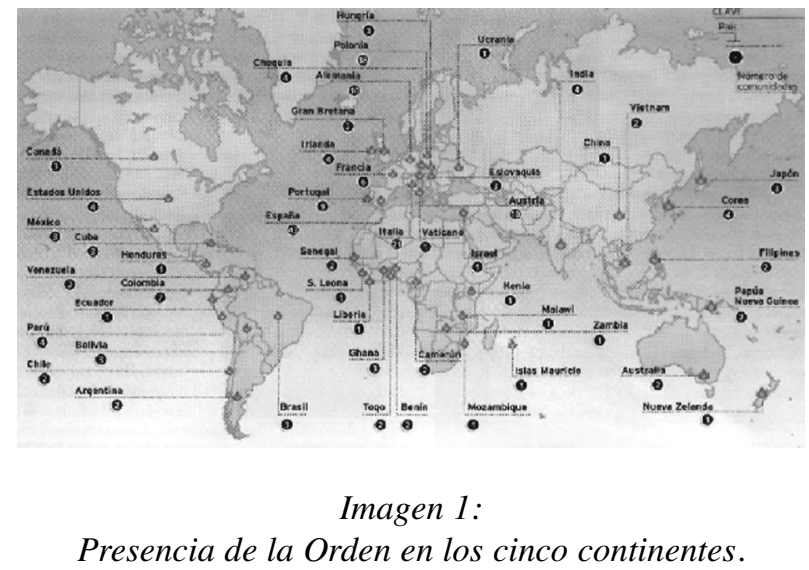

